\title{
Nutrition and maternal morbidity and mortality
}

\author{
Andrew Tomkins \\ Centre for International Child Health, Institute of Child Health, 30 Guilford Street, London WC1N 1EH, UK
}

\begin{abstract}
Nearly 600000 women die every year from pregnancy related conditions and the maternal mortality rates (MMR = deaths per 100000 live births) in developing countries may be as high as 1000 compared with less than ten in industrialised countries. In the light of the striking impact of deficiencies of micronutrients such as vitamin A and zinc on immune function, morbidity and mortality in children it seems reasonable to suggest that such deficiencies might play a contributing role in the high rates of morbidity and mortality in mothers. Hitherto, there has been rather little published on the contribution of malnutrition to maternal morbidity or mortality but recent results of micronutrient supplementation show a major effect of vitamin A or beta carotene supplementation on maternal mortality in Nepal and an impressive effect of a multiple micronutrient mixture on pregnancy outcome in Tanzania. There is now data showing that subclinical mastitis, a potential risk factor for mother to child transmission of HIV by increasing levels of virus in breast milk, is influenced by maternal diet in Tanzania and feeding patterns in South Africa. Considering the massive tragedy of maternal mortality the recent data provides opportunities for new, innovative nutritional interventions for the reduction of the global burden of maternal morbidity and mortality.
\end{abstract}

Infection: Pregnancy: Illness: Micronutrients: Human Immunodeficiency Virus: Vitamin A

\section{Measurement issues and trends}

Maternal mortality rates (MMR) are calculated as deaths per 100000 births, extending from 28 weeks of pregnancy to 6 weeks postpartum. Where there is vital registration with accurate recording of births and deaths it is possible to make assessments of secular changes in MMR and to compare such changes with specific interventions. Unfortunately, most developing countries do not have vital registration and alternative techniques have to be used including indirect interview methods such as the 'sisterhood' method where women are interviewed about the occurrence of a pregnancy-related death in the family. There are advantages and disadvantages of all these techniques, the greatest problem being under-reporting. A comparison of MMR using three data sources was performed in Matlab, Bangladesh (Ronsmans et al. 1998). The investigators compared maternal deaths identified through a unique demographic surveillance system (DSS), using a previous detailed investigation into the levels and causes of maternal mortality, and deaths identified in a special study of lay reporting. There were important and substantial disagreements between the routine reporting and the special studies, and up to $50 \%$ differences in MMR using the different approaches. This has important implications for any monitoring or evaluation of programmes aimed at reducing MMR (Ronsmans et al. 1997).
Thus randomised controlled clinical trials with rigorous recording of demographic indices are especially important in establishing the evidence base for nutritional interventions aimed at reducing maternal morbidity and mortality.

Globally, around 600000 women die every year from pregnancy related causes. Many of these women are short, thin, and anaemic and have a variety of micronutrient deficiencies. Malnutrition is associated with increased risk of morbidity and mortality in children; even allowing for the confounding socio-economic factors which caused them to be malnourished in the first place (Tomkins \& Watson, 1989). Similarly the low anthropometric scores and micronutrient deficiencies are associated with impaired function of different aspect of the immune response (Waterlow et al. 1992). Thus it is strongly intuitive to conclude that malnutrition contributes to the high rates of maternal morbidity and mortality in developing countries but it is only recently that randomised controlled clinical trials of the effect of nutrition interventions on maternal morbidity and mortality have been published (West et al. 1999) (Fawzi et al. 1998).

Prior to these there have been rather negative reviews on the role of nutrition, drawing on limited secular analyses of the changes in maternal mortality in the UK (Loudon, 1992; Loudon, 2000). MMR at the beginning of the nineteenth century was around 1000 - higher than in most countries today; it fell gradually over the following decades 
but was still high until the mid-1930s. Several major concurrent changes were noted including improved standards of care at delivery, a reduction in the virulence of Streptococcus pyogenes, the availability of antibiotics, such as sulphonamides and penicillin, the widespread use of ergometrine to reduce postpartum haemorrhage, increased use of blood transfusion and better training and facilities for good obstetric practice (Loudon, 1987). Many of these are still not widely available in developing countries and the nutritional status of women in many developing countries is far worse than in Europe, even in the nineteenth century.

Recent reviews of the possible interventions to prevent mortality from induced abortion, puerperal infection and pregnancy induced hypertension suggested that there is insufficient evidence for an important role for nutrition (Rush, 2000; Stein et al. 1978). They also suggest it may not be beneficial, from the perspective of risk of obstructed labour, to promote increased food intake during pregnancy. However interpretation of the reasons for differences in Caesarean section rates as an indicator of pelvic disproportion is fraught with difficulty because of the many factors influencing whether to perform surgery or not. Overall, despite the strongly argued concerns by Rush (Rush, 2000) and Garner (Garner et al. 1992) there is little evidence of an increased prevalence of obstructed labour among women receiving dietary supplementation. Indeed in one of the most careful studies of nutritional supplementation and pregnancy outcome, in the Gambia, there was no evidence of increased obstetric complications even though birth weight increased significantly (Ceesay et al. 1997). In addition there was clear evidence of a reduction in perinatal mortality rate. There has, until recently, been insufficient information on whether there is a separate impact, in terms of pregnancy outcome, of improvement in micronutrient status as distinct from an overall improvement in anthropometric indices.

A review of data from Bangladesh (Goodburn et al. 1995) and a global review (Liskin, 1992) conclude that maternal morbidities appear to occur frequently but very little is known about their magnitude or causes. Goodburn et al. (1995) points out that women's beliefs about disease causation have profound importance on the way that they live, seek treatment and feel. In the absence of studies which have carefully compared symptoms with more rigorous indices of inflammation (Darling et al. 1999), it has been difficult to conclude much about the prevalence, let alone the impact of nutrition on morbidity. The recent data from Nepal are very instructive (Christian et al. 1998; Christian et al. 2000a).

\section{Descriptive studies of causes of maternal mortality}

There are important differences in the cause of maternal mortality between communities and countries; these may well influence the degree of impact that nutritional interventions may have. In Indonesia haemorrhage, infection and toxaemia of pregnancy accounted for $91 \%$ of deaths resulting in an MMR of 390 (Chi et al. 1981). In Bloemfontein in South Africa, MMR was 720 with puerperal sepsis and post-abortion sepsis accounting for $46 \%$ of the deaths (Cooreman et al. 1989). An early study from Zambia in the 1970s showed an MMR of 1500. The commonest deaths in order of importance were toxaemia, septicaemia, haemorrhage and ruptured uterus. At that time, $32 \%$ of women had received no antenatal care (Hickey \& Kasonde, 1977).

In the Gambia in the early 1990s, MMR, excluding nonabortion causes, was 736 (Hoestermann et al. 1996). Among the direct causes in order of importance, haemorrhage, toxaemia of pregnancy, sepsis and anaemia were all major contributing causes to maternal mortality. A longitudinal study of a rural area in the Gambia in which there have been intense nutritional and medical interventions over a period of 10 years, showed remarkable reductions in perinatal mortality (from 110 to 45), infant mortality (from 148 to 24), and mortality in the under 5s (from 109 to 13) (Lamb et al. 1984). There were no pregnancy related maternal deaths in this community over a period of 8 years, during which time 16 would have been expected given current estimates for MMR. The authors concluded that nutrition interventions and the 24-hour availability of a physician and/or qualified midwife were the reason why a dramatic response had been achieved but they were not able to dissect the relative importance of the nutritional component of the intervention. A retrospective study evaluating the particular problems of adolescent maternal mortality, with very little intervention, was performed in Burkina Faso showing that the adolescent MMR was 4081 - one of the highest MMR ever recorded; the most frequent causes of death were abortion and chronic anaemia (Lankoande et al. 1999). The importance of improved care for the vulnerable pregnant teenager has been highlighted again recently (Brabin et al. 1998).

During a review of the community programmes in Matlab, Bangladesh it was noted that obstetric related deaths had declined strikingly in the intervention area (where a package of mother and child health interventions had been introduced) but not in the control area (Ronsmans et al. 1997). This decline was attributed primarily to the posting of midwives at the village level and the appointment of doctors at the local maternity clinics. The authors suggested that these staff played a key role in improving delivery services and providing early recognition of obstetric problems and increasingly referred complex cases to a local government hospital where Caesarean sections and blood transfusions were available. There were no specific nutrition interventions.

During a study of the impact of malaria control in Mangochi in Southern Malawi, an MMR of 370 was calculated but there was no report on whether malaria control reduced the prevalence of maternal morbidity (McDermott et al. 1996). A randomised control trial of the impact of frequent versus infrequent home visiting by midwives to women who had recently delivered in Zambia, demonstrated interesting findings in relation to morbidity (Ransjo-Arvidson et al. 1998). Those visited more frequently, visited health centres more frequently for illnesses in themselves or their infants, however details of the maternal illnesses were not described. The sample was too small to detect improved recognition and treatment of postpartum complications.

A recent retrospective analysis of MMR in a hospital 
based study in Kwazulu Natal, South Africa showed an overall MMR of 144, the main causes of death being toxaemia of pregnancy and haemorrhage (Moodley et al. 1996). Less than half of the women who died attended an antenatal clinic. There is no data on the MMR among those, evidently the majority of women, who for one reason or another did not attend a health facility for their delivery. An MMR of below 100 was noted in Cape Town, possibly due to the greater use of the obstetric 'flying squad' (van Coeverden de Groot HA, 1979). Around half of the patients who died had not received antenatal care. The commonest causes of maternal death were, in order of priority, toxaemia of pregnancy, haemorrhage, cardiac disease, pulmonary embolism, sepsis, trauma and anaesthetic complications. An analysis of hospital based maternal mortality in Turkey showed an MMR of 822 (Ayhan et al. 1994). Seventy-seven per cent of the deaths were due to direct obstetric causes including toxaemia, infection and haemorrhage.

It appears that there is considerable heterogeneity in the rates and causes, both direct and non-direct, of maternal mortality. MMR may be relatively easy to measure given support for a large population study but the difficulties in assessing causes of mortality remain. This has implications for assessing the reasons for any differential impact that nutritional interventions may have.

\section{Association between malnutrition and infection}

Faisel \& Pitroff (Faisel \& Pittrof, 2000) have recently reviewed the interaction between vitamin A and causes of maternal mortality, emphasising the possible association and biological plausibility. They indicate prospective studies on women who had low vitamin A levels in the blood during the second trimester of pregnancy and throughout the postpartum period. These women had an increased risk of puerperal infection. The recently published Nepal vitamin A study also showed that pregnant women with night blindness were twice as likely to develop genito-urinary infections than women without night blindness (Christian et al. 2000b). However, the impact of systemic infection and metabolic stress on vitamin $\mathrm{A}$ is well documented and in most of these studies it is almost impossible to know which came first - either the metabolic or infective stress or the low plasma vitamin A.

A detailed assessment of nutritional interventions for the prevention of maternal morbidity was recently published using a meta-analysis of the few randomised-controlled trials (Kulier et al. 1998). Several studies show an association between high levels of plasma ferritin in the third trimester and very preterm delivery and clinical infections, emphasising the effect of the inflammatory response on markers that are traditionally used for assessing micronutrient status (Goldenberg et al. 1996). Ferritin is remarkable in its lability in response to infection and other markers such as transferrin receptors have been used more frequently. One of the most striking examples of the interaction between inflammation and plasma/serum levels of infection is the increase in ferritin levels in pregnant women with a high prevalence of infection, almost precluding the use of ferritin as an indicator of iron status in pregnancy in certain populations. Recent studies have examined the possible use of transferrin receptors as better markers of iron status in inflammation. Their levels are much less perturbed by inflammation than ferritin but there are significant changes during episodes of malaria for instance (Beesley et al. 2000). The role of iron deficiency in contributing to the high rates of morbidity in pregnancy is not established even though improving iron status as a means to prevent the development of anaemia is usually accepted.

While there is increasing recognition of the high prevalence of intestinal helminths in pregnant women, and an appreciation of the improved pregnancy outcome if deworming is provided (de Silva et al. 1996; de Silva et al. 1999) there is little evidence on the role of nutrition in increasing susceptibility to intestinal helminths. Limited studies of micronutrients in relation to schistosomiasis in Zimbabwe have identified a close association between micronutrient deficiency, especially zinc, and schistosomiasis (Friis et al. 1996). The impact of zinc deficiency on intestinal response to enteric pathogens is well recognised (Roy et al. 1997), but a putative role for nutritional deficiency in relation to increased susceptibility for gut helminths in humans is not established. Iodine deficiency is associated with increased rates of stillbirth, premature delivery and spontaneous abortion. How much these potentially dangerous conditions contribute to maternal morbidity and mortality has not been studied though the risks are evident (Hetzel, 1989; Delange, 2000).

\section{Micronutrient interventions and maternal morbidity and mortality}

While there is virtually no data (using post-mortem confirmation of clinical diagnosis) in developing countries on the specific direct causes (i.e. those which are thought to be the final cause of death) of maternal mortality, improved clinical awareness and the use of verbal autopsy give some clues.

A recent study in Nepal (West et al. 1999) shows a remarkable reduction in maternal mortality as a result of supplementation with beta carotene or vitamin A. A total of 44646 married women, of whom 20119 became pregnant were included in the study. The women were randomised to receive, weekly, a single oral supplement of placebo, vitamin $\mathrm{A}(7000 \mu \mathrm{g} \mathrm{RE})$ or $\beta$ carotene (42 $\mathrm{mg}$ or $7000 \mathrm{RE})$ for over 3.5 years. All causes of mortality in women during pregnancy up to 12 weeks postpartum (pregnancy related mortality) and mortality during pregnancy to 6 weeks postpartum, excluding deaths apparently related to injury (maternal mortality) were used as the main outcome measures. Mortality related to pregnancy in the placebo, vitamin $A$ and $\beta$ carotene groups was 704, 426 and 361 deaths per 100000 pregnancies, giving relative risks of 0.60 and 0.51 among those who received vitamin $A$ and $\beta$ carotene, respectively. Combined, vitamin A or $\beta$ carotene lowered mortality by $44 \%$ and reduced the maternal mortality rate ratio from 645 to 385 deaths per 100000 live births. Important causes of maternal mortality, in order of frequency, were obstetric-related causes, eclampsia, haemorrhage, sepsis and injury. There was not sufficient 
statistical power to ascribe the mortality impact of vitamin A or $\beta$ carotene to their effect on one cause of mortality rather than another. This important study is the only one published to date describing the impact of a micronutrient supplementation on maternal mortality. Others are underway; it will be especially interesting to know how much micronutrients impact on maternal mortality in areas where infections, such as malaria and HIV for example, are common.

Within the framework of this large study an analysis of the impact of these supplements on symptoms of illness was performed (Christian et al. 2000a). There was no impact of either supplement on morbidity rates reported up to 28 weeks of gestation, inclusive. However in late pregnancy ( $>28$ weeks), symptoms of nausea, faintness and night blindness were reduced with vitamin $A$, but not $\beta$ carotene supplementation. Vitamin A supplementation shortened the length of labour by $1.5 \mathrm{~h}$ and $50 \mathrm{~min}$ among nulliparous and multiparous women, respectively. Both interventions reduced the postpartum prevalence of at least four loose stools and night blindness. $\beta$ Carotene supplementation also reduced the number of episodes of high fever postpartum. The mean number of days of any reported illness symptoms was 3-4 per week throughout pregnancy. Among women receiving vitamin A, the total number of days of illness symptoms accrued over the last 12 weeks of pregnancy was lower by 5 days compared with the placebo recipients. There are very few publications on rates of morbidity among pregnant women and the above study has the only data published to date describing the impact of a micronutrient supplementation on morbidity. Interestingly, there were earlier reports of the development of diarrhoea and malabsorption syndromes associated with pregnancy in South Africa (Jacobson, 1972; Moshal et al. 1973) and Singapore (Whitfield, 1967). These were originally attributed to deficiency of folic acid, but it seems possible that vitamin A deficiency might also have played a role.

A study of 1075 HIV positive women in Dar es Salaam, Tanzania examined the impact of vitamin A with or without micronutrients (20 mg B1, $20 \mathrm{mg} \mathrm{B} 2,25 \mathrm{mg} \mathrm{B} 6$, $100 \mathrm{mg}$ niacin, $50 \mathrm{mg} \mathrm{B} 12,500 \mathrm{mg}$ vitamin $\mathrm{C}, 30 \mathrm{mg}$ vitamin $\mathrm{E}$ and $0.8 \mathrm{mg}$ folic acid) on pregnancy outcome. Women were recruited at between 12 and 27 weeks gestation and received their regular supply of antenatal iron and folic acid. They were randomised to receive placebo, vitamin A, a mixture of multivitamins without vitamin A, or a mixture of multivitamins including vitamin A. There were 30 fetal deaths in the women receiving multivitamins compared with 49 among those not receiving multivitamins. The prevalence of low birth weight $(<2500 \mathrm{~g})$ was $15.8 \%$ in those receiving placebo and $8.8 \%$ in those receiving the multivitamins. The prevalence of severe prematurity $(<37$ weeks) was $10.2 \%$ in those receiving placebo and $6.2 \%$ in those receiving multiple micronutrients. Interestingly, vitamin A did not affect any of the pregnancy related variables. Multivitamins, but not vitamin $\mathrm{A}$, resulted in an increase in CD4, CD8 and CD3 counts. This is the only published study on the effect of multivitamins on such outcomes to date.

A recent study of the impact of daily supplements of vitamin A and zinc in preventing puerperal sepsis has been conducted in Indonesia using body temperature as an indicator of puerperal sepsis (Hakimi et al. 1999). Sepsis was scored on the basis of a body temperature of $>38^{\circ} \mathrm{C}$ on at least 1 of the 14 days postpartum that they were visited. There was an elevated body temperature in only $2.8 \%$ of women receiving vitamin $\mathrm{A}$, compared with $9.3 \%$ of women receiving placebo.

A review of the impact of vitamin A supplements as 'anti-infective' interventions (Semba, 1999) describes the earlier work of supplementation with cod liver oil as a protection against puerperal sepsis in the UK. Using various criteria for puerperal sepsis there was a lower incidence among women receiving cod liver oil than among those who did not. In view of the recent interest in the immunological effect of vitamin D (Wilkinson et al. 2000), the high concentration of vitamin D in cod liver oil may also have been important; it would be interesting to explore this in future studies.

An acute phase metabolic response may be shown by significantly higher levels of serum C-reactive proteins. A study in Tanzania, which examined the impact of dietary supplementation with sunflower seed oil which is rich in tocopherols, showed that pregnant women receiving this oil had lower acute phase protein levels in the postpartum period compared with a control group of women (Filteau et al. 1999). The sample size was too small to be able to relate these changes to the clinical outcome but it raises the possibility that improved antioxidant intake may reduce maternal morbidity. Perhaps the changes in immunological indices and pregnancy outcome observed among Tanzanian women receiving multiple vitamin supplements is attributable to the high dose of vitamin $\mathrm{E}$ in that study (Fawzi et al. 1998). No data on the effect of antioxidants other than $\beta$ carotene on maternal morbidity have been reported so far. In view of the considerable interest in the role of vitamin $\mathrm{E}$ in the structure of the viral genome and the tissue response to pathogens it seems that assessment of the impact of vitamin E supplementation on infection in HIV subjects is particularly important (Beck, 2000; Beck \& Levander, 2000).

In recent studies among lactating women in several developing countries the presence of subclinical mastitis has been documented (Willumsen et al. 1999). This condition involves an increase in permeability in the capillary/mammary cell junction leading to an increase in sodium content of the milk. Increased cytokine concentrations are present and have a close correlation with $\mathrm{Na} / \mathrm{K}$ levels in breast milk, so close in fact that $\mathrm{Na} / \mathrm{K}$ can be used to monitor the inflammatory process. The precise biology of this condition has not yet been identified but it has considerable functional significance. Subclinical mastitis is associated with higher levels of viral load in the breast milk of HIV positive mothers. It is also associated with growth faltering, presumably due to decreased breast milk production. Two key factors have been identified recently as risk factors for subclinical mastitis. First, the infant feeding pattern; mothers who breast-feed exclusively have a lower prevalence of subclinical mastitis compared with those who use mixed feeding. Second, systemic infection; postpartum sepsis and malaria are associated with increased $\mathrm{Na} / \mathrm{K}$ 
levels which fall as the temperature responds to treatment. Presumably the increased circulating cytokines from a systemic infection increase the breast milk levels and induce an increased sodium secretion. It is not yet clear how common this condition is but published studies show that sub clinical mastitis is present in a quarter of the women studied in Bangladesh, Tanzania, Malawi and South Africa (Willumsen et al. 2000).

\section{Toxaemia of pregnancy}

In a review of the possible links between nutrition and toxaemia, numerous theories have been examined (Maine, 2000). Interestingly, somewhat like the MMR, there has been remarkable reduction in the rates of toxaemia in some populations over periods of time where nutrition has not changed at all and vice versa. She concludes that there is no available evidence to show a role of nutrition in reducing rates of maternal mortality from toxaemia. Others conclude that the relationships are there. There is considerable interest in the pathology of the placenta in relation to preeclampsia and toxaemia of pregnancy. Several studies have examined the placental production of lipid peroxides; Wang has shown that activities of copper and zinc dependent enzymes and the tissue levels of vitamin A are significantly lower in pre-eclamptic compared to normal placentas (Wang \& Walsh, 1996). The activity of catalyse is significantly higher and it is speculated that decreased antioxidant activity may result in increased lipid peroxide levels in pre-eclamptic toxaemia leading to local pathology and a cascade of immunological events leading to increased blood pressure. Yanik examined the antioxidant status of subjects with pre-eclampsia and eclampsia, comparing them with normo-tensive pregnant women (Yanik et al. 1999). Both the pre-eclamptic and eclamptic patients had higher levels of serum malondialdehyde and lower vitamin E levels. Malondialdehyde levels were significantly correlated with systolic and diastolic blood pressure, suggesting that the imbalance between lipid peroxidation and serum vitamin $\mathrm{E}$ levels is not only responsible for abnormalities in the placenta but may have contributed to hypertension.

\section{Programme implications}

Women in developing countries are frequently malnourished and often have a poor pregnancy outcome. The new data shows the close link between malnutrition and illness or death during pregnancy and lactation. Until now, most programmes on Safer Motherhood have paid little attention to improving nutrition. Improving obstetric care is an obviously crucial, but insufficient, step for safer motherhood. The current evidence suggests that improvement of vitamin A status in the preconceptual and pregnancy periods produces significant changes in mortality and some decrease in morbidity. It is not yet known if supplementation starting in pregnancy is as effective. Moreover it is not yet clear as to how much reduction in mortality could be achieved by improving vitamin A status in a country where antenatal, midwifery and obstetric care are better developed. There are also striking improvements in pregnancy outcome as a result of a certain combination of micronutrients. It is not known whether this is the optimal combination of micronutrients or whether the improvement in pregnancy outcome as a result of multiple micronutrients given in pregnancy is the same among HIV negative mothers. Neither is it known if such an effect would be observed where malaria or tuberculosis is common. Studies providing answers to these questions are needed urgently.

From a programmatic perspective, there are many interventions required to bring down the appallingly high MMR in developing countries. Safer motherhood regimes have traditionally focused on improving antenatal care and delivery services together with improvement in women's status and life-style over the years. There have been improvements in MMR in some countries as a result of such programmes but MMR is still at devastatingly high levels in many and even increasing in some. There is now growing support for micronutrient enhancement even though it is not yet possible to say how much pregnancy related morbidity and mortality will be influenced by nutritional interventions in different situations. It is now possible to improve micronutrient status of pregnant and lactating women (Huffman et al. 1998; Alnwick, 1998). Dietary diversification, food fortification and supplementation are all possible and there are different strategies for the short and long term which take account of sustainability and affordability. There is no place for a slavish doctrinaire approach which claims that there is only one way of improving nutrition of girls and women in order to prevent them from becoming ill or dying in pregnancy. Those who espouse one approach for the improvement of nutrition while deprecating another need to acknowledge the new and emerging evidence that lives can be saved as a result of micronutrient supplements. Families, communities, local authorities, national governments and international agencies want to improve the nutritional status of women. The challenge for nutritional researchers is to provide information on the scale of the benefits in a variety of situations using different interventions.

\section{Acknowledgements}

This review was conducted using data that was generated as a result of financial support from the Wellcome Trust, Department for International Development, Virgin Airways, and the Research and Development Group of Great Ormond Street Hospital. Research at the Institute of Child Health and Great Ormond Street Hospital for Children NHS Trust benefits from R\&D funding received from the NHS executive.

\section{References}

Alnwick DJ (1998) Combating micronutrient deficiencies: problems and perspectives. Proceedings of the Nutrition Society 57, 137-147.

Ayhan A, Bilgin F, Tuncer ZS, Tuncer R, Yanik A \& Kisnisci HA (1994) Trends in maternal mortality at a university hospital in 
Turkey. International Journal of Gynecology \& Obstetrics 44, 223-228.

Beck MA (2000) Nutritionally induced oxidative stress: effect on viral disease. American Journal of Clinical Nutrition $\mathbf{7 1}$, 1676 S-1681S.

Beck MA \& Levander OA (2000) Host nutritional status and its effect on a viral pathogen. Journal of Infectious Diseases 182, S93-S96.

Beesley R, Filteau S, Tomkins A, Doherty T, Ayles H, Reid A, Ellman T \& Parton S (2000) Impact of acute malaria on plasma concentrations of transferrin receptors. Transactions of the Royal Society of Tropical Medicine and Hygiene 94, 295-298.

Brabin L, Verhoeff FH, Kazembe P, Brabin BJ, Chimsuku L \& Broadhead R (1998) Improving antenatal care for pregnant adolescents in southern Malawi. Acta Obstetricia et Gynecologica Scandinavica 77, 402-409.

Ceesay SM, Prentice AM, Cole TJ, Foord F, Weaver LT, Poskitt EM \& Whitehead RG (1997) Effects on birth weight and perinatal mortality of maternal dietary supplements in rural Gambia: 5 year randomised controlled trial. British Medical Journal 315, 786-790.

Chi IC, Agoestina T \& Harbin J (1981) Maternal mortality at twelve teaching hospitals in Indonesia-an epidemiologic analysis. International Journal of Gynecology \& Obstetrics 19, 259-266.

Christian P, Schulze K, Stoltzfus RJ \& West KP Jr (1998) Hyporetinolemia, illness symptoms, and acute phase protein response in pregnant women with and without night blindness. American Journal of Clinical Nutrition 67, 237-1243.

Christian P, West KP Jr, Khatry SK, Katz J, LeClerq SC, Kimbrough-Pradhan E, Dali SM \& Shrestha SR (2000a) Vitamin A or beta-carotene supplementation reduces symptoms of illness in pregnant and lactating Nepali women. Journal of Nutrition 130, 2675-2682.

Christian P, West KP Jr, Khatry SK, Kimbrough-Pradhan E, LeClerq SC, Katz J, Shrestha SR, Dali SM \& Sommer A (2000b) Night blindness during pregnancy and subsequent mortality among women in Nepal: effects of vitamin A and beta-carotene supplementation. American Journal of Epidemiology 152, 542-547.

Cooreman BF, Cronje HS \& Grobler CJ (1989) Maternal deaths at Pelonomi Hospital Bloemfontein, 1980-1985. A survey of 81 consecutive cases. South African Medical Journal 76, 24-26.

Darling JC, Filteau SM, Kitundu JA, Kingamkono RR, Msengi AE \& Tomkins AM (1999) Acute phase proteins as markers of systemic illness in acute diarrhoea. Acta Paediatrica 88, 259-264.

de Silva NR, Kodituwakku KK, Edirisinghe SS \& de Silva HJ (1996) Routine use of mebendazole in pregnancy. Ceylon Medical Journal 41, 99-101.

de Silva NR, Sirisena JL, Gunasekera DP, Ismail MM \& de Silva HJ (1999) Effect of mebendazole therapy during pregnancy on birth outcome. Lancet 353, 1145-1149.

Delange F (2000) The role of iodine in brain development. Proceedings of the Nutrition Society 59, 75-79.

Faisel H \& Pittrof R (2000) Vitamin A and causes of maternal mortality: association and biological plausibility. Public Health Nutrition 3, 321-327.

Fawzi WW, Msamanga GI, Spiegelman D, Urassa EJ, McGrath N, Mwakagile D, Antelman G, Mbise R, Herrera G, Kapiga S, Willett W \& Hunter DJ (1998) Randomised trial of effects of vitamin supplements on pregnancy outcomes and $\mathrm{T}$ cell counts in HIV-1-infected women in Tanzania. Lancet 351, 1477-1482.

Filteau SM, Lietz G, Mulokozi G, Bilotta S, Henry CJ \& Tomkins AM (1999) Milk cytokines and subclinical breast inflammation in Tanzanian women: effects of dietary red palm oil or sunflower oil supplementation. Immunology 97, 595-600.

Friis H, Ndhlovu P, Kaondera K, Sandstrom B, Michaelsen KF, Vennervald BJ \& Christensen NO (1996) Serum concentration of micronutrients in relation to schistosomiasis and indicators of infection: a cross-sectional study among rural Zimbabwean schoolchildren. European Journal of Clinical Nutrition 50, 386-391.

Garner P, Kramer MS \& Chalmers I (1992) Might efforts to increase birthweight in undernourished women do more harm than good? Lancet 340, 1021-1023.

Goldenberg RL, Tamura T, DuBard M, Johnston KE, Copper RL \& Neggers Y (1996) Plasma ferritin and pregnancy outcome. American Journal of Obstetrics \& Gynecology 175, 13561359.

Goodburn EA, Gazi R \& Chowdhury M (1995) Beliefs and practices regarding delivery and postpartum maternal morbidity in rural Bangladesh. Studies in Family Planning 26, 22-32.

Hakimi M, Dibley MJ, Suryono A, Nurdiati D, Th Ninuk SH, Dawiesah Ismadi S (1999) Impact of vitamin A and zinc supplements on maternal postpartum infections in rural central Java. IVACG Abstracts, Durban.

Hetzel BS (1989) The Story of Iodine Deficiency an International Challenge to Nutrition. New York: Oxford University Press.

Hickey MU \& Kasonde JM (1977) Maternal mortality at University Teaching Hospital, Lusaka. Medical Journal of Zambia 11, 74-78.

Hoestermann CF, Ogbaselassie G, Wacker J \& Bastert G (1996) Maternal mortality in the main referral hospital in The Gambia, West Africa. Tropical Medicine and International Health 1, 710-717.

Huffman SL, Baker J, Shumann J, Zehner ER, (1998) The case for promoting multiple vitamin/mineral supplements for women of reproductive age in developing countries. pp. 1-40, Linkages, AED, USAID.

Jacobson RJ (1972) Puerperal folate deficiency resembling tropical sprue. South African Medical Journal 46, 1103.

Kulier R, de Onis M, Gulmezoglu AM \& Villar J (1998) Nutritional interventions for the prevention of maternal morbidity. International Journal of Gynecology \& Obstetrics 63, 231-246.

Lamb WH, Foord FA, Lamb CM \& Whitehead RG (1984) Changes in maternal and child mortality rates in three isolated Gambian villages over ten years. Lancet 2, 912-914.

Lankoande J, Ouedraogo CM, Ouedraogo A, Tieba B, Akotionga M, Sanou J \& Kone B (1999) Maternal mortality in adolescents at the university hospital of Ouagadougu. Review Medicales Brussels 1999, 87-89.

Liskin LS (1992) Maternal morbidity in developing countries: a review and comments. International Journal of Gynecology \& Obstetrics 37, 77-87.

Loudon I (1987) Puerperal fever, the streptococcus, and the sulphonamides, 1911-1945. British Medical Journal (Clinical Research Edition) 295, 485-490.

Loudon I (1992) The transformation of maternal mortality. British Medical Journal 305, 1557-1560.

Loudon I (2000) Maternal mortality in the past and its relevance to developing countries today. American Journal of Clinical Nutrition 72 (1 Suppl), 241S-246S.

Maine D (2000) Role of nutrition in the prevention of toxemia. American Journal of Clinical Nutrition 72, (1 Suppl), 298S$300 \mathrm{~S}$.

McDermott JM, Slutsker L, Steketee RW, Wirima JJ, Breman JG \& Heymann DL (1996) Prospective assessment of mortality among a cohort of pregnant women in rural Malawi. American Journal of Tropical Medicine and Hygiene 55, (1 Suppl), 66-70. 
Moodley D, Payne AJ \& Moodley J (1996) Maternal mortality in Kwazulu/Natal: need for an information database system and confidential enquiry into maternal deaths in developing countries. Tropical Doctors 26, 1-5.

Moshal MG, Hift W, Kallichurum S \& Pillay K (1973) Malabsorption and its causes in Natal. South African Medical Journal 47, 1093-1103.

Ransjo-Arvidson AB, Chintu K, Ng'andu N, Eriksson B, Susu B, Christensson K \& Diwan VK (1998) Maternal and infant health problems after normal childbirth: a randomised controlled study in Zambia. Journal of Epidemiology and Community Health 52, 385-391.

Ronsmans C, Vanneste AM, Chakraborty J \& Van Ginneken J (1998) A comparison of three verbal autopsy methods to ascertain levels and causes of maternal deaths in Matlab, Bangladesh. International Journal of Epidemiology 27, 660666.

Ronsmans C, Vanneste AM, Chakraborty J \& Van Ginneken J (1997) Decline in maternal mortality in Matlab, Bangladesh: a cautionary tale. Lancet 350, 1810-1814.

Roy SK, Haider R, Tomkins AM \& Behrens R (1989) Effect of systemic infection on intestinal permeability in Bangladeshi children with persistent diarrhea. In Malnutrition in Chronic Diet-Associated Infantile Diarrhoea, pp. 385-389. New York: Academic Press.

Roy SK, Tomkins AM, Akramuzzaman SM, Behrens RH, Haider R, Mahalanabis D \& Fuchs G (1997) Randomised controlled trial of zinc supplementation in malnourished Bangladeshi children with acute diarrhoea. Archives of Diseases of Childhood 77, 196-200.

Rush D (2000) Nutrition and maternal mortality in the developing world. American Journal of Clinical Nutrition 72, (1 Suppl), 212S-240S.

Semba RD (1999) Vitamin A as 'anti-infective' therapy 19201940. Journal of Nutrition 129, 783-791.

Stein Z, Susser M \& Rush D (1978) Prenatal nutrition and birth weight: experiments and quasi-experiments in the past decade. Journal of Reproductive Medicine 21, 287-299.

Tomkins A \& Watson F (1989) Malnutrition and Infection: A Review (United Nations Administrative Committee on Coordination/Subcommittee on Nutrition, WHO, Geneva.

van Coeverden de Groot HA (1979) Trends in maternal mortality in Cape Town. South African Medical Journal 1953-1977 56, 547-552.

Wang Y \& Walsh SW (1996) Antioxidant activities and mRNA expression of superoxide dismutase, catalase, and glutathione peroxidase in normal and preeclamptic placentas. Journal of the Society for Gynecological Investigations 3, 179-184.

Waterlow JC, Tomkins AM \& Grantham-Mcgregor SM (1992) Protein Energy Malnutrition. London: Edward Arnold.

West KP Jr, Katz J, Khatry SK, LeClerq SC, Pradhan EK, Shrestha SR, Connor PB, Dali SM, Christian P, Pokhrel RP \& Sommer A (1999) Double blind, cluster randomised trial of low dose supplementation with vitamin A or beta carotene on mortality related to pregnancy in Nepal. The NNIPS-2 Study Group. British Medical Journal 318, 570-575.

Whitfield CR (1967) Sprue complicating pregnancy in Singapore. Journal of Obstetrics \& Gynecology of British Commonwealth 74, 537-543.

Wilkinson RJ, Llewelyn M, Toossi Z, Patel P, Pasvol G, Lalvani A, Wright D, Latif M \& Davidson RN (2000) Influence of vitamin D deficiency and vitamin D receptor polymorphisms on tuberculosis among Gujarati Asians in west London: a casecontrol study. Lancet 355, 618-621.

Willumsen JF, Filteau SM, Coutsoudis A, Underwood BA, Newell ML \& Tomkins AM (2000) Subclinical mastitis as a risk factor for mother-infant, HIV transmission. In Advances in Experimental Medicine and Biology 478, 211-213.

Yanik FF, Amanvermez R, Yanik A, Celik C \& Kokcu A (1999) Pre-eclampsia associated with increased lipid peroxidation and decreased serum vitamin E levels. International Journal of Gynecology \& Obstetrics 64, 27-33. 